\title{
Work in Progress: Fostering Cross-Disciplinary Collaborations between Biomed- ical Engineering and Occupational Therapy Students - A Model for Clinical Exposure for BME
}

\section{Dr. Patricia A. Meyers, American International College}

Patricia A. Meyers OTD, OTR/L is an Assistant Professor of Occupational Therapy at American International College in Springfield, MA. Dr. Meyers received a BS in Occupational Therapy from Boston University and a Post-Professional Doctorate in Occupational Therapy from Rocky Mountain University of Health Professions. Her areas of instruction are in the subjects of kinesiology, introduction to occupational therapy, management, adaptive technology and adult physical disabilities. These reflect her interest in the history, philosophy and current research in the profession. Her work experience incorporated interprofessional collaboration which she believes has positively influenced practical application in the classroom. This experience has also contributed to her interest in interprofessional education (IPE) as a component of student curriculum and expanded to assistive technology where occupational therapy and engineering students collaborate on project designs. Her interest and research in IPE has led to local, national and international presentations related to this subject matter. She has extensive clinical experience treating clients in the area of upper extremity outpatient orthopedics and cumulative trauma disorders, specializing in industrial rehabilitation as well as industrial and office ergonomics.

\section{Dr. Judy L. Cezeaux, Western New England University}

Judy Cezeaux is Professor and Chair of Biomedical Engineering at Western New England University in Springfield, Massachusetts. She received her B.S. degree in mechanical engineering from Carnegie Mellon University and her Ph.D. degree in biomedical engineering from Rensselaer Polytechnic Institute. Prior to her appointment at Western New England University, she was a Senior Staff Fellow at the National Institute for Occupational Safety and Health in Morgantown, West Virginia as well as a faculty member at the University of Tennessee, Knoxville. 


\section{Work in Progress: Fostering Cross-Disciplinary Collaborations between Biomedical Engineering and Occupational Therapy Students: A Model for Clinical Exposures for BME}

\section{Background}

Collaborations between occupational therapy and engineering student design teams are not a new concept. In some cases, first-year engineering students work on design projects for individuals with disabilities as an introduction to the design process [1], [2]. In general, design teams will interact with occupational therapists or physical therapists, and patients to develop a custom design suited to the specific needs of a patient. More often, design for individuals with disabilities occurs in capstone engineering or engineering technology courses, again often involving design for a single individual [3] - [6], with occupational therapists serving as project advisors. We describe a collaboration between occupational therapy and engineering students and faculty at neighboring institutions.

\section{Description of Collaborative Student Experience}

In this student collaborative method, it is the occupational therapy student who first develops a prototype of a low technology device. Using a constructivist approach to learning, an assignment is presented in an introductory assistive technology class offered in the fall semester as part of the MSOT curriculum. Occupational therapy students are asked to build a prototype of a custom assistive technology (AT) device and provide a training manual for this original design. An expectation of this assignment is that the occupational therapy students articulate the inspiration for their low technology device and how they envision this will increase ease and independent participation in an individual's valued task or activity. The prototypes are expected to be well-constructed, safe, and easy to use and do what the student says it will do. In creating their prototype, the occupational therapy students focus on universal design, rather than design for an individual. This assignment was developed as a kinesthetic learning experience encouraging transformative learning. The students explain the purpose, rationale, potential target population as well as demonstrate their prototype. The summer following the completion of this introductory assistive technology course, faculty members in occupational therapy and engineering meet to discuss which projects are best suited for further development. Occupational therapy students who have expressed an interest and whose projects have the potential for universal design, pitch their AT device to student engineering teams. The biomedical engineering students are either in the first semester of their capstone design course or in a product development course. Not all occupational therapy AT projects presented to the engineering design teams are chosen for further development. Once projects are chosen, the occupational therapy student becomes a member of the design team and assists in defining the need and market for the device as well as participates in the validation of the final design. In contrast to other collaborations between engineering and occupational therapy in design of assistive technologies, there is no direct client for the design, rather a population that can benefit from the universal design developed by the OT/engineering design team. Occupational therapy and engineering faculty co-advise the design projects during this time. The outcome from the design teams is a refined prototype that meets the customer needs as defined by the occupational therapy students and any technical specifications developed by the engineering students to ensure 
the proper and safe function of the device. Advantages for the occupational therapy students include gaining a deeper appreciation of the design process as well as witnessing the project development of their low technology prototypes. Engineering students gain a peer team member who provides the clinical context for the project. A desired outcome is that the project serves as a catalyst for interdisciplinary interactions, and that the students demonstrate a maturity regarding the understanding of their individual professions and the unique perspectives both bring to the successful development and fabrication of a low technology prototype. This process has yielded a patented consumer device which may have widespread appeal.

\section{Assessment of Collaborative Student Experience}

Using an anonymous survey, approved by the Institutional Review Boards at the respective institutions, occupational therapy and engineering student attitudes about the AT project collaboration were measured. Responses from a total of 5 out of 8 students were received. The results are shown in Tables 1-3. From Table 1, 4 out of 5 students felt that they gained knowledge of the other profession and felt that the interdisciplinary team meetings were effective in determining the form of the final design.

Table 1: Student perceptions on the interdisciplinary project collaboration (data represent number of responses)

Through my interaction with other disciplines, my understanding of the other profession (OT for ENGR, ENGR for OT) involved in this collaboration has changed. $(n=5)$

\begin{tabular}{|c|c|c|c|c|}
\hline Not at all & A little & Somewhat & Significantly & A lot \\
\hline 1 & 0 & 0 & 3 & 1 \\
\hline \hline \multicolumn{5}{|c|}{ The interdisciplinary meetings were effective in shaping the final project design $(\mathrm{n}=5)$} \\
\hline Not at all & A little & Somewhat & Significantly & A lot \\
\hline 0 & 1 & 0 & 1 & 3 \\
\hline
\end{tabular}

Student's perceptions on their likelihood to pursue similar collaborative projects in their professional careers are shown in Table 2. While 4 students believe that the knowledge gained may be useful in their professional career, only 3 students report that they are likely to pursue a similar collaboration.

Table 2: Student perceptions on their likelihood to pursue collaborative projects (data represent number of responses)

Would you be likely to pursue a similar collaboration in your professional career after this experience? $(\mathrm{n}=5)$

\begin{tabular}{|c|c|c|c|c|}
\hline Not at all likely & Perhaps & Neutral & Likely & Quite likely \\
\hline 1 & 0 & 1 & 0 & 3 \\
\hline \hline
\end{tabular}

Do you feel the knowledge gained in this collaboration will be useful in your professional career? $(\mathrm{n}=5)$

\begin{tabular}{|c|c|c|c|c|}
\hline Not at all likely & Perhaps & Neutral & Likely & Quite likely \\
\hline 0 & 1 & 0 & 1 & 3 \\
\hline
\end{tabular}


When asked about knowledge gained about the other discipline, 3 students reported an increase in knowledge about the design process while 4 students gave a broad range of answers related to the importance of understanding of the needs of the client, as shown in Table 3. Note that there were 7 total responses to these two questions, thus 2 respondents answered both of these questions. It is impossible, therefore, to pinpoint thoughts of each discipline's students/alumni.

Table 3: Student perceptions on the knowledge gained about the other discipline (data represent number of responses)

\begin{tabular}{|c|c|c|c|c|}
\hline \multicolumn{5}{|c|}{$\begin{array}{l}\text { FOR OT STUDENTS/OT ALUMS ONLY: My understanding of the engineering design } \\
\text { process has changed }(\mathrm{n}=3)\end{array}$} \\
\hline $\begin{array}{l}\text { Strongly } \\
\text { disagree }\end{array}$ & Disagree & $\begin{array}{l}\text { Neither agree } \\
\text { nor disagree }\end{array}$ & Agree & Strongly agree \\
\hline 0 & 0 & 0 & 0 & 3 \\
\hline \multicolumn{5}{|c|}{$\begin{array}{l}\text { FOR ENGR STUDENTS/ENGR ALUMS ONLY: My understanding of the importance of } \\
\text { considering the individual needs of the client in device design has changed }(n=4)\end{array}$} \\
\hline $\begin{array}{l}\text { Strongly } \\
\text { disagree }\end{array}$ & Disagree & $\begin{array}{l}\text { Neither agree } \\
\text { nor disagree }\end{array}$ & Agree & Strongly agree \\
\hline 0 & 1 & 1 & 1 & 1 \\
\hline
\end{tabular}

Two open ended questions at the end of the survey asked what worked best as well as what could be improved during the collaboration. Responses for what worked best included:

- Being able to collaborate face to face with engineering students to agree on a final design that incorporates a holistic OT approach, as well as engineering components

- Having periodic meetings to get their feedback and to make sure we were on the same page as them

- Meetings and collaboration between students and faculty.

As to what could be improved, student responses included:

- I would have incorporated more "in person" meeting times to even further collaboration and understanding of each other's backgrounds/knowledge to best suit the end product.

- Better communication/follow through on progress of prototype between engineering students and OT students.

- More communication

- Further explanation of the careers

Discussion

Interprofessional collaboration of healthcare professionals develops a respect and appreciation for other disciplines and contributes to efficient and cost-effective care with improved patient outcomes. Despite the proximity of the institutions and the availability of technology including group emails, texts and Skype ${ }^{\mathrm{TM}}$, based on student feedback, the need for improved communication throughout the design process is indicated. Consideration at the initial face to face meeting between the interdisciplinary student product design team include: completing a semester long meeting schedule and outlining responsibilities and expectations for each student 
team member specific to communication and project deadlines. This would assist with keeping the project on schedule. From a faculty perspective, the occupational therapy student expectations for potential AT product development and interdisciplinary collaboration has been formally added to the assignment description for the design of a low technology device. Also, discussion points about the various engineering professions and their relationship to AT and occupational therapy has been incorporated into the course content of this introductory assistive technology course. In the engineering design courses, addressing the need for engineers to better appreciate client values and input when considering customer needs for their design is being implemented. Due to the small sample size, we cannot yet determine if the primary goal of the interdisciplinary project was accomplished. This collaboration has been implemented through two student cohorts with the third to begin in the upcoming months, which will provide an opportunity to gain additional data on student insights about interprofessional collaboration on an AT design project. The applicability of such a collaboration to other BME programs may be limited if their or neighboring institutions do not have an occupational therapy major.

References

[1] B. Ankenman, J. Colgate, P. Jacob, R. Elliot, and S. Benjamin, "Leveraging rehabilitation needs into freshman engineering design projects," in Proceedings of the American Society for Engineering Education (ASEE) 2006 Annual Conference \& Exposition, Chicago, IL, 2006. [Online]. Available: https://peer.asee.org/1166

[2] T. McBride, V. Bergel, and J. Fullerton, "Community-based projects by first-year engineering students," in Proceedings of the American Society for Engineering Education (ASEE) 2005 Annual Conference \& Exposition, Portland, OR, 2005. [Online]. Available: https://peer.asee.org/14212

[3] D. R. Waryoba, L. Demi, and A. Fatula, "A case study of interprofessional collaboration between engineering and health sciences students at Penn State DuBois," in Proceedings of the 6th IEEE Integrated STEM Education Conference - ISEC 2016, Princeton, NJ, 2016. [Online]. Available: http://ieeexplore.ieee.org/document/7457552/

[4] S. Warren, P. Prakash, E. Brokesh, and G. W. Singleton, "Design projects to quantify the health and development of autistic children," in Proceedings of the American Society for Engineering Education (ASEE) 2014 Annual Conference \& Exposition, Indianapolis, IN, 2014. [Online]. Available: https://peer.asee.org/20265

[5] A. W. Eberhardt, L. K. Vogtle, and G. Edwards, "Senior designs to aid the disabled: the UAB experience," in Advances in Bioengineering - 1999 (The ASME International Mechanical Engineering Congress and Exposition), Nashville, TN, 1999.

[6] R. L. Goldberg and K. Caves, "Work in progress: Using clinical advisory boards and an online system to provide feedback for client-based senior design projects," in Proceedings of the American Society for Engineering Education (ASEE) 2013 Annual Conference \& Exposition, Atlanta, GA, 2013. [Online]. Available: https://peer.asee.org/22772 